\title{
A liderança como intersubjetividade lingüística
}

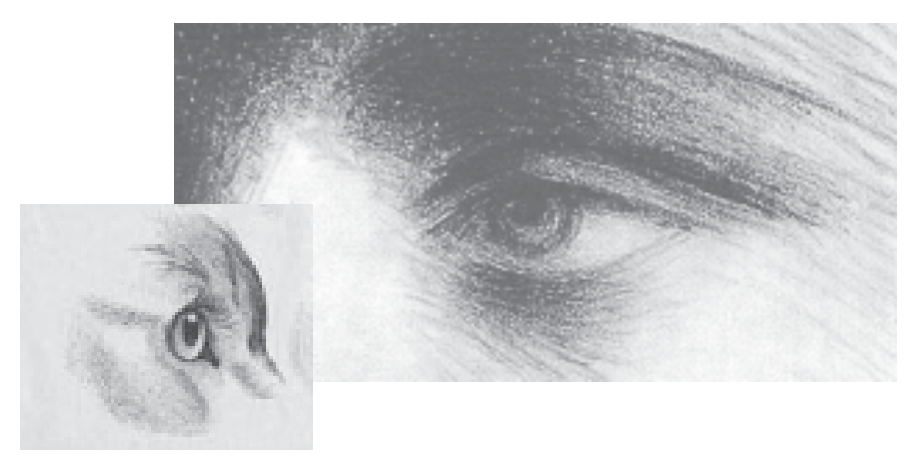

Francisco Javier Uribe Rivera ${ }^{1}$

Elizabeth Artmann²

RIVERA, F. J. U.; ARTMANN, E. Leadership as a function of linguistics intersubjectivity. Interface - Comunic., Saúde, Educ., v.10, n.20, p.411-26, jul/dez 2006.

This paper sums up some concepts regarding leadership and seeks to highlight the growing importance of the vision of a leader in assisting in organizational learning, based on team-work, and in coordinating linguistic communication processes oriented towards understanding the organization's mission, structure, and dynamics. Upholding that, in addition to their ability to implement strategic management, leaders must also develop communication skills and support change, in order to manage more effectively intersubjective relationships among organizational subjects, to make the organization more competent.

KEY WORDS: leadership. personnel management. organizations.

Este artigo traz uma síntese de várias concepções de liderança e seu objetivo é destacar a importância crescente da visão do líder como instância da aprendizagem organizacional, de base coletiva, e coordenador de processos de comunicação lingüística cujo telos é o consenso sobre a imagem, a estrutura e a dinâmica de funcionamento das organizações. Sustentamos que, além de capacidades de análise estratégica, o líder deve desenvolver competências comunicativas e apoiar a mudança para gerir com mais eficácia as relações intersubjetivas dos atores organizacionais, tornando a organização competente.

PALAVRAS-CHAVE: liderança. administração de recursos humanos. organizações.

${ }^{1}$ Pesquisador, Departamento de Administração e Planejamento de Saúde, Escola Nacional de Saúde Pública, Fiocruz (DAPS/ENPS/ FIOCRUZ).<uribe@ensp.fiocruz.br>

2 Pesquisadora, DAPS/ENSP/FIOCRUZ. <artmann@ensp.fiocruz.br>

${ }^{1}$ Rua Almirante Alexandrino, 3780, apto. 201, Bloco E1

Santa Tereza - Rio de Janeiro, RJ

Brasil - 20.241-266 


\section{Apresentação}

Neste trabalho, fazemos uma síntese de quatro concepções de liderança: a da liderança transformadora, de Warren Bennis (1985, 1999), da Universidade da Califórnia do Sul, e consultor especializado no tema; o enfoque de liderança da Escola da Organização que Aprende (Learning Organization), representada por Peter Senge (1997, 2000), professor da Escola de Administração do Instituto de Tecnologia de Massachusetts (MIT); a concepção de liderança estratégica de Paulo Roberto Motta (1991), da Fundação Getúlio Vargas/RJ; e a noção de liderança como fenômeno lingüístico, que podemos atribuir, em grande medida, ao professor Fernando Flores, acadêmico e consultor em Gestão, especialista em Filosofia da Linguagem. Esta análise comparativa visa distinguir os pontos comuns, que corresponderiam a um questionamento da liderança carismática, vertical e tradicional, e a uma afirmação de um tipo de liderança comunicativa, caracterizada pelo desenvolvimento de algumas competências aqui apresentadas. Por fim, defendemos a noção de liderança coletiva ou comunicativa como a mais adequada ao gerenciamento do setor saúde, considerando suas características específicas.

\section{A liderança na perspectiva de Bennis}

Na distinção polar que Bennis (1985 apud Crozier \& Sérieyx, 1994) estabelece entre liderança e gestão, a primeira sabe o que é necessário fazer e o que é certo, enquanto o gestor sabe como fazer as coisas de forma certa (quadro 1).

Quadro 1. Distinção entre gestão e liderança.

\begin{tabular}{|l|l|}
\hline Gestão (fazer bem as coisas) & Liderança (saber o que fazer) \\
\hline Preocupação maior com: & Preocupação maior com: \\
- Administração & - Inovação \\
- Manutenção & - Desenvolvimento \\
- Sistema /Estrutura & - Gente/Confiança \\
- Curto prazo & - Longo prazo \\
- Como? & - O Quê? Por quê? \\
- Sistemas, recursos, tecnologias & - Visão \\
- Obediência & - Comprometimento \\
- Controle & - Poder \\
\hline
\end{tabular}

Fonte: Crozier \& Sérieyx apud Rivera, 2003.

Para justificar esta polarização um tanto rígida, o autor sustenta que as organizações sofreriam de uma saturação de gestão "procedimental" e de uma ausência flagrante de liderança. Em função desta falta, as organizações teriam concentrado suas energias nos instrumentos de gestão, criando muitas vezes monstros burocráticos. Seria necessário contrabalançar a gestão burocrática com liderança, entendida como uma abordagem da condução preocupada com a inovação e a mudança (desenvolvimento), as pessoas, a visão futura de 
organização, o comprometimento e o poder. A liderança é vista como o uso justo do poder, como energia fundamental para lançar e sustentar uma ação ou para traduzir intenção em realidade.

Posteriormente, o autor procura compensar essa polarização afirmando que uma das habilidades primordiais da liderança seria conjugar capacidade visionária com capacidade gerencial, realçando a capacidade de apresentar e de obter resultados (Bennis, 2001).

O modelo gerencial defendido pelo autor como o mais adequado para as preocupações de uma liderança transformadora seria a gestão por objetivos, por meio de projetos integradores e dinâmicos, desenvolvidos por equipes interdisciplinares com grande autonomia. Dentro desta perspectiva de reforço das equipes ou dos grupos, o discurso do autor se aproxima da concepção de uma liderança mais disseminada ou coletiva.

De fato, para Bennis \& Nanus (1988), a liderança não se relaciona com a posição hierárquica ou com a função exercida; nas organizações modernas, cada trabalhador deveria ser o líder de alguém, sobretudo dele mesmo Essa compreensão coincide com o questionamento teórico feito por eles a cinco grandes mitos: a) a liderança é um dom raro; b) os líderes são inatos, não feitos; c) são carismáticos; d) só existe liderança no escalão mais alto da organização; e) o líder controla, dirige, estimula, manipula. Na esteira dessa crítica, a liderança é percebida como resultado de processos de aprendizagem, no qual é importante o envolvimento na criação de um clima amplo de interação de idéias, de um modelo organizacional e de uma arquitetura social que permitam gerar capital intelectual e ajudem a liberar o poder de cada pessoa/equipe de trabalho (Bennis, 2001).

Ao analisar as habilidades ou requisitos da liderança transformadora, o autor prioriza a formulação da imagem de futuro da organização e a comunicação sobre a mesma. Segundo Crozier \& Sérieyx (1994), Bennis sustenta que essa imagem/visão teria a capacidade de incentivar uma mobilização dos sujeitos organizacionais, na medida em que fizesse com que estes descubram novos horizontes, ou na medida em que a visão ilumine novas possibilidades de ação.

A visão/imagem organizacional corresponderia a um sonho/desejo que deve ser partilhado, comunicado, objetivando a adesão do corpo organizacional. A habilidade de justificar comunicativamente a visão seria, portanto, um dos requisitos básicos da liderança.

A construção da visão organizacional supõe colocar-se um passo à frente para se ter uma perspectiva sobre o que está acontecendo, especialmente quando os cenários da empresa se tornam cada vez mais complexos (Bennis; 2001), e se subentende a paixão para atingi-la.

Para que a mobilização em torno de uma imagem organizacional possa ser efetiva, o líder deve, igualmente, inspirar confiança, a qual estaria relacionada não só à noção de 'ser exemplo', mas também à postura de constância $e$ coerência. A melhor maneira de demonstrar a coerência, além do seu próprio comportamento, seria passar de intenções a atos concretos modificando, por exemplo, de forma positiva, os processos de gestão e a estrutura organizacional (Bennis, 1985, apud Crozier \& Sérieyx, 1994).

Contudo, a concepção de liderança de Bennis é uma construção contraditória, pois, embora, em alguns momentos se insira discursivamente na 
proposta de uma liderança disseminada, como potencial de aprendizagem coletiva, predomina, ainda, nesse autor, a concepção de liderança visionária, que se apóia na prerrogativa exclusiva de sintetizar a visão por meio de processos não aprofundados teoricamente. Todo o discurso do autor explora uma semântica recorrente sobre líderes fortes e vigorosos. Por exemplo, a afirmação taxativa de que todo grande grupo tem um líder vigoroso (Bennis $\mathcal{E}$ Biederman, 1999); a afirmação de que, se temos líderes fortes desde o início, eles criarão atitudes e um ambiente no qual a liderança poderá se desenvolver (Bennis, 2001); ou a afirmação de cunho estratégico de que a criatividade de um grande grupo supõe a presença ou a invenção do inimigo externo (Bennis, 1999).

Esta interpretação um tanto personalista da liderança, que atribui ao líder possibilidades exageradas de conduzir o conjunto organizacional para a mudança, em detrimento de uma construção coletiva, não considera condições resultantes de restrições sistêmicas e de complexas interações entre os sujeitos organizacionais, as quais ficam subsumidas à sua interpretação e direção.

Em termos críticos, podemos sustentar que, embora encontremos aspectos comunicativos presentes no modelo de Bennis, estes ficam subsumidos pela busca da adesão do coletivo a uma visão predeterminada pelo líder, o que traz um caráter um tanto indutor e estratégico à formulação da visão.

\section{A liderança como potencial de aprendizagem coletiva}

Senge (apud Starkey, 1997) caracteriza os requisitos ou novas habilidades que a liderança da organização que aprende deveria incorporar. Para ele, o líder deve ser um idealizador, professor e regente.

No exercício do primeiro papel, a liderança se envolve como idealizador dos propósitos da organização e, de sua tradução prática, das políticas e estratégias, construídas coletivamente. Se a responsabilidade primeira da liderança é com esse planejamento, isto não quer dizer que o ato seja solitário. O termo construção coletiva sugere conceber o processo de planejamento das políticas e estratégias como um processo de aprendizagem organizacional ampla. Citando Mintzberg (1985), o autor assume que o planejamento não pode ser visto como um esquema racional elaborado no plano abstrato e implementado em toda a extensão da organização, mas como um fenômeno emergente. Organizações de sucesso "fabricam sua estratégia", uma vez que estão continuamente aprendendo com as constantes mudanças nas condições dos negócios, ponderando o desejável e o factível. O segredo não está em obter a estratégia certa, mas sim em promover o pensamento estratégico. A escolha do projeto específico é apenas parte da necessidade do criador da política. O mais importante é a necessidade de conseguir enxergar a complexidade e formular conceitos e visões de mundo para lidar com essa complexidade. A promoção de um ambiente de aprendizagem por meio da difusão do pensamento estratégico seria uma das funções essenciais da liderança.

O líder-professor corresponde à visão do mentor, do guia, do facilitador. Seus objetivos fundamentais seriam trazer à tona e ajudar a reestruturar os modelos mentais e as visões da realidade das pessoas, promovendo o pensamento sistêmico, no sentido de buscar as causas estruturais ou profundas dos fenômenos e suas relações. 
O líder-regente é uma instância que se compenetra dos ideais de alta responsabilidade que caracterizam uma organização que aprende e que se coloca a serviço dos interesses superiores da organização. O conceito de uma liderança que presta serviços (servant leadership) é o oposto da liderança egocêntrica.

Entre as habilidades que a liderança deve desenvolver, Senge destaca:

- A construção de visões compartilhadas, implicando em alguns requisitos: a) o líder deve saber comunicar sua visão e pedir apoio, no sentido de conferir se ela merece o comprometimento dos outros e de questionar seu ponto de vista, assumindo uma construção interativa; b) as visões pessoais devem ser estimuladas, e não anuladas; c) a construção da visão é um processo contínuo, que não se deixa apreender pela figura da "declaração da missão" em reuniões especiais, mas que corresponde à difusão do pensamento estratégico capaz de apoiar o questionamento quotidiano do que realmente queremos conseguir em cada circunstância prática; d) a liderança deve poder combinar visões extrínsecas (do tipo vencer um concorrente) com visões intrínsecas (criar um novo produto, um novo padrão de satisfação de necessidades); e) a liderança deve saber distinguir visões positivas (alicerçadas em aspirações) e negativas (baseadas no medo), fortalecendo as primeiras.

- Trazer à tona e testar modelos mentais, considerando os requisitos: a) a possibilidade de perceber saltos de abstração, questionando generalizações; b) equilibrar indagação e argumentação, assumindo que situações complexas exigem um aprendizado cooperativo; c) distinguir a teoria assumida (o que alguém diz que faz) da teoria em uso, entendendo (com base em Argyris, 1992) que uma distância entre o declarado e o implícito é crítica para o aprendizado; d) reconhecer e dissipar rotinas defensivas.

- Desenvolver o pensamento sistêmico, que corresponde a: a) enxergar inter-relações, não coisas, processos, não fotos instantâneas; b) ir além das acusações, assumindo que a fonte das falhas não está nas pessoas, mas nos sistemas; c) concentrar-se na complexidade dinâmica (saber relacionar causas e efeitos distantes no tempo e espaço e distinguir conseqüências remotas), e não na complexidade de detalhes; d) concentrar-se, em termos da ação, em áreas de alta alavancagem; e) evitar soluções sintomáticas.

- Criar uma rede de proteção para a reflexão individual e coletiva, capaz de sustentar a possibilidade da inovação e da mudança. Aqui, a capacidade de garantir um tempo livre para a reflexão dos sujeitos organizacionais é fundamental.

Em "A dança das mudanças", Senge (2000) desenvolve a versão mais atualizada de sua noção de liderança. Valendo-se da metáfora do jardim, o autor se contrapõe à imagem do lider-herói. O líder "jardineiro" não é o que, prostrado sobre as plantas, brada: "Cresçam plantas, cresçam com afinco". Essa liderança, ao contrário, reconhece que o crescimento depende de seu potencial e decide acompanhar seu ciclo natural, preocupando-se com as condições que reforçam e que limitam seu crescimento como água, solo, nutrientes, sol, outras árvores. Subjacente a esta imagem, está a idéia de que as organizações devem ser vistas como sistemas biológicos, e não como máquinas, cuja peça defeituosa deve ser trocada. No caso do jardim, uma planta não morre para ser substituída por outra, simplesmente. O que acontece é que uma nova vai crescendo $e$ acaba por tomar o lugar da velha. O mesmo ocorre com o 
comportamento. Se um comportamento novo é mais eficaz do que o antigo, então, o novo acaba conquistando espaço. Desta maneira, o líder-jardineiro seria aquele que tenta atuar sobre as condições limitadoras e promotoras do desenvolvimento potencial das pessoas organizacionais, especialmente sobre as condições básicas para uma aprendizagem coletiva solidária. Embora a metáfora do jardim possa ser simplista, ao pensarmos sobre organizações complexas como as da área da saúde, o que destacamos da proposta de Senge são as condições de aprendizado como fatores propulsores ou realizadores do potencial de crescimento das pessoas, potencial esse que poderia ser tolhido em contextos impositivos e objetivantes.

A liderança, para Senge, não seria um fator individual. Sua visão de liderança corresponde a uma capacidade coletiva para moldar as mudanças. $\mathrm{Na}$ organização, haveria vários líderes, em várias instâncias, e não necessariamente executivos. Destacam-se, dentre eles, os "que portam a semente", isto é, aqueles que detêm a capacidade de estabelecer redes mais ou menos informais de comunicação, de impulsionar em todos os níveis, em relações de transversalidade, a possibilidade da transferência de habilidades e de conhecimentos. Esses líderes retirariam seu potencial da capacidade de estabelecer interconexões entre inovadores.

Para o autor, os grandes problemas que a mudança enfrenta são de tipo gerencial. Estes referem-se: à incapacidade de gerar uma dinâmica de negociação de uma visão compartilhada; à dificuldade de trazer a tona temas "indiscutíveis" mediante o desenvolvimento das habilidades de reflexão $e$ indagação; à tendência de evitar o enfrentamento das causas mais complexas dos problemas em prol de um tratamento baseado nos sintomas; a um tipo de conduta defensiva que escamoteia medidas que podem afetar interesses, entre outros.

Essas restrições podem ser compensadas por intermédio de estratégias de aprendizagem. Mas isto não é suficiente. A mudança exigiria uma maior concentração sobre os aspectos limitadores do crescimento, entendendo mudança não como troca ou substituição, ou produção de algo absolutamente novo, mas como crescimento ou como evolução do novo a partir do antigo. Para Senge (2000), a partir de Maturana (1998), o reconhecimento de tendências naturais de compensação ou de limitação do crescimento deve ser o alvo privilegiado de uma reflexão estratégica sobre como agir para enfraquecer ou atenuar essas tendências e para adiar os momentos de inflexão compensadora. Toda esta reflexão aponta para a necessidade de pensar não em termos de impor mudanças, mas de cultivar mudanças.

Esta perspectiva não pretende afirmar que a liderança não possa ser individual. Contudo, o foco reflete sobre as relações entre capacidades individuais e sociais. Pretende-se aqui, reforçar a idéia de que líder é quem fomenta os processos de aprendizagem que podem gerar uma liderança disseminada e de que o desenvolvimento da liderança como instância individual depende de interações típicas do fenômeno social da aprendizagem.

\section{A liderança da gestão estratégica}

Para Motta (1991), a essência da liderança consiste em capacidades de domínio do contexto (análise estratégica do ambiente e dos problemas organizacionais, 
previsão de futuro e formulação da visão), de manejo intersubjetivo (comunicação e negociação) e individuais (como o bom conhecimento de si, a capacidade de socialização e a autenticidade).

Sobre as habilidades organizacionais, o autor salienta:

- O bom conhecimento da missão e dos objetivos internos, para que estes possam ser comunicados, e das características da ambiência externa, de modo a facilitar a interação da empresa com a realidade existente.

- A capacidade de descoberta permanente e de processamento contínuo de problemas e soluções.

- A capacidade de articular, agregar e processar continuamente idéias e alternativas de ação para redefinir o sistema de autoridade e de responsabilidade, com base em valores compartilhados.

- Formulação de uma visão (intuição sobre o futuro) e capacidade de orientar-se em termos prospectivos.

Em relação às habilidades interpessoais, o autor destaca:

- A capacidade de aprender a aceitar as pessoas como realmente são e de reconhecer o seu valor positivo.

- Estimular o contato direto permanente com as pessoas, aumentando a confiança mútua.

- Desenvolver as capacidades de comunicação e de negociação, reforçando o compartilhamento de informações, a interação permanente e a participação.

- Praticar um tipo de gestão que contribua para diminuir a distância social. A respeito das habilidades individuais, Motta considera que devam ser encaradas de maneira flexível, por serem passíveis de aprendizado ou não necessariamente inatas. Destaca algumas habilidades básicas, como: o bom conhecimento de si mesmo, de suas potencialidades e limitações; a iniciativa; o otimismo; a persistência; a integridade e autenticidade. Reforçando a dimensão subjetiva, o autor se detém na importância do ilógico e da intuição na gestão administrativa, que explicam o caráter às vezes pouco coerente e racional da mesma. Para ele, a intuição mistura elementos de racionalidade formal $e$ informal e apóia-se fortemente na experiência acumulada pela liderança. A dimensão subjetiva não-formal ou racional da liderança reforça, aqui, um argumento importante de não-omissão da natureza individual da mesma.

$O$ autor sintetiza as qualidades da liderança, usando o quadro:

Quadro 2. Mitos e realidades sobre liderança.

\begin{tabular}{|c|c|}
\hline Liderança não é & Liderança é \\
\hline 1. mágica ou mistério & 1. habilidade humana e gerencial \\
\hline 2. propriedade de pessoas eminentes & 2. alcançável por pessoas comuns \\
\hline 3. fruto de qualidades especiais inatas & $\begin{array}{l}\text { 3. produto de habilidades e conhecimentos } \\
\text { aprendidos }\end{array}$ \\
\hline $\begin{array}{l}\text { 4. panacéia para a solução de todos os } \\
\text { problemas }\end{array}$ & $\begin{array}{l}\text { 4. forma de comunicação e articulação de uma } \\
\text { missão e de futuros alternativos }\end{array}$ \\
\hline $\begin{array}{l}\text { 5. uso do poder pessoal para garantir } \\
\text { seguidores ou propósitos pessoais }\end{array}$ & $\begin{array}{l}\text { 5. uso do poder existente para garantir o } \\
\text { alcance de propósitos comuns }\end{array}$ \\
\hline
\end{tabular}

Fonte: Motta,1991. p.222. 


\section{A liderança como fenômeno lingüístico}

A concepção de liderança como fenômeno lingüístico foi desenvolvida por Flores $(1989,2004)$ e Echeverria $(1997,2000)$. Estes autores aplicam a taxonomia dos atos de fala de Austin (1962) e Searle (1976) ao campo organizacional. Estes últimos entendem os enunciados lingüísticos como formas de interação social que geram compromissos e, por essa característica, correspondem a formas de ação que precedem outras ações. O caráter de ação do ato de fala deve-se à sua potencialidade para criar novas realidades no mundo. Assim, esses autores questionam a visão representacional da linguagem, que se limita a reconhecer a sua condição de representação de realidades do mundo objetivo, de nomear objetos preexistentes. Ao invés disso, postulam a capacidade de a linguagem criar realidades. As declarações, por exemplo, são atos de fala que, diferentemente das afirmações, não pretendem dar conta de um estado de coisas no mundo, mas que têm o poder de transformá-lo. São atos que, quando proferidos, geram uma nova realidade no mundo. A contratação ou a demissão de pessoal pertence ao universo dos atos declarativos administrativos. Quando um juiz declara um par marido e mulher, está criando uma nova realidade só possível com base nessa declaração, ancorada numa autoridade reconhecida para tal. Esta questão é importante: declarações precisam estar ancoradas na autoridade; legitimidade do ator"sujeito que as profere. A tomada de decisões corresponde, em geral, ao terreno das declarações.

Ainda em relação à concepção da linguagem como geradora de compromissos, Austin e Searle sustentam que, nas várias classes de atos de fala, os atores ou interlocutores se comprometem com algo, variando a natureza desse compromisso e o critério de aferição do mesmo. Por exemplo, no caso dos atos constatativos ou das afirmações, os locutores se comprometem a fornecer, se for necessário, evidências, razões ou garantias que apóiem as afirmações, de modo a ingressar em processos argumentativos que mostrem a veracidade das mesmas (compromisso com a verdade). Por outro lado, no caso dos atos compromissários, os locutores se comprometem com a sinceridade das promessas assumidas, com a disponibilidade de competência para impulsionar esses compromissos, $e$, com a responsabilidade, que implica não mudar a prioridade das promessas assumidas no percurso posterior à declaração das mesmas. No caso das petições, os locutores se comprometem com a sinceridade e consistência das mesmas, que significa a disposição de não voltar atrás. Assim, em todos os atos de fala, os atores contraem compromissos, seja com a verdade da afirmação proferida, com a sinceridade a respeito das promessas feitas ou com a consistência de suas petições.

O nível de cumprimento desses compromissos lingüísticos está na base de um determinado juízo sobre a confiança que a fala e ação de um ator/locutor suscita nos outros atores. Os juízos são uma forma especial das declarações. Segundo Echeveria (2000), os juízos representam formas de avaliação valorativa, que adquirem matizes específicos dentro da classe das declarações. Quando declaramos que tal pessoa é competente para coordenar reuniões, emitimos um juízo que pode ser contestado - esta condição pode ou não ser reconhecida por outros. Assim, um juízo supõe sempre a possibilidade do contrário. Os juízos contribuem para reduzir a complexidade ou incerteza do 
mesmo, para aumentar os níveis de confiança em relação ao futuro. No caso do juízo anterior, este sugere que a pessoa aludida seja indicada no futuro para coordenar reuniões. Mas, a solidez dos juízos depende do passado, da apresentação de fatos ou experiências do passado por meio dos quais seja possível mostrar ou evidenciar tal capacidade. Os juízos precisam ser fundamentados por intermédio de afirmações ou constatações de situações do passado, responsáveis por sua solidez, ao mesmo tempo em que se referem ao futuro. Quando dizemos que um médico é bom, emitimos um julgamento que suscita confiança. O juízo é um tipo de enunciado lingüístico voltado para o futuro, que nos ajuda a restringir possibilidades futuras, que nos permite seguir com um determinado médico e estabelecer com ele uma relação pautada pela credibilidade, ancorada em seus atos coerentes, consistentes, responsáveis, acertados (Artmann \& Rivera, 2006).

\footnotetext{
É no processo da interação... que nós podemos fundamentar os juízos que permanentemente fazemos sobre a fala $e$ a capacidade do outro, sobre a disposição do outro. Dizem os autores aludidos (Flores \& Echeverria) que os juízos sobre a confiança que fazemos remetem, em última instância, a juízos de caráter ético, representados pelo respeito mútuo. (Artmann \& Rivera, 2006, p.24)
}

A liderança dentro desse contexto interpretativo expressa um juízo sobre a capacidade de alguém estabelecido pela coletividade. A liderança existe para a coletividade, não é uma realidade objetiva divorciada da avaliação feita. Esta avaliação é um juízo sobre a fala e a ação dos líderes. Representa um juízo sobre: a veracidade das narrativas situacionais do líder (e da informação por ele fornecida); a autenticidade e a consistência de suas petições; a autenticidade e grau de responsabilidade das promessas e compromissos assumidos; a autoridade que fundamenta suas declarações $e$ a consistência das mesmas; $e$, finalmente, uma avaliação sobre os juízos que a própria liderança estabelece sobre a sua competência e a dos outros, ou seja, um juízo sobre a solidez desses julgamentos.

Echeverria (2000) articula a esse juízo sobre a liderança uma teoria da confiança. Sustenta que a confiança é uma resultante do grau de cumprimento dos compromissos sociais inerentes às diferentes classes de atos de fala proferidos pela liderança no exercício do poder. A confiança, portanto, implica: (1) capacidade de escutar; (2) competência para fornecer e usar informação verdadeira, sobre a qual apóia-se o processo de tomada de decisões. Esta capacidade corresponde ao entendimento de que as afirmações, como atos de fala, iluminam a situação onde atuaremos; (3) capacidade de declarar, em função de uma autoridade reconhecida ou legítima, e de ser consistente com as declarações; (4) capacidade de fundamentar os juízos e de receber juízos críticos, e (5) capacidade de mostrar sinceridade, competência $e$ responsabilidade no exercício dos compromissos.

Um rompimento dos níveis de compromisso declarados com a fala se traduziria em uma diminuição da confiança $e$ avaliação negativa da liderança de alguém.

Flores (2004) critica a abordagem tradicional do fenômeno da liderança, que oscila entre a compreensão como capacidade de comandar e como 
capacidade visionária. Para ele, a primeira visão é estreita na medida em que os líderes não apenas conseguem que as coisas sejam feitas, mas também são os inventores do que pode ser feito. A segunda visão é questionada quando esta compreensão visionária se refere a algo misterioso, mágico ou inato, que alguns poucos detêm, ou seja, a uma capacidade que não poderia ser objeto de aprendizagem ou desenho.

$\mathrm{O}$ autor chama a atenção sobre o algo comum e amplamente aceito às várias acepções do fenômeno da liderança: (1) a capacidade de gerar um sentido de pertencimento a uma comunidade, uma identidade coletiva, uma mobilização em torno de uma causa comum; (2) a contribuição como fonte de significado para as pessoas, afetando suas identidades e suas formas de interpretação do mundo e o futuro; (3) a relação com a questão do poder, que, nesta medida, representaria a capacidade de motivar, de ampliar as possibilidades de ação das comunidades. Apesar de conterem aspectos parcialmente válidos, todas as acepções tradicionais, para o autor, são limitadas, pois enfocam o fenômeno do ponto de vista de seus resultados, e não de sua geração. Para Flores, a necessidade de explicar e produzir o fenômeno da liderança, de enfocar como este é gerado, leva-o a discutir as relações entre linguagem e liderança. As competências que geram a liderança são essencialmente lingüísticas, e, entre estas, o autor destaca as seguintes:

- A capacidade de ler o mundo. As narrativas que um ator realiza sobre mundo o fazem colocar-se a si mesmo, ao referir o mundo a preocupações $e$ interesses humanos. Uma narrativa abre e fecha possibilidades de ação. Um aspecto importante desta capacidade é a competência para ler o mundo considerando as narrativas dos outros. Outro aspecto refere-se à capacidade de distinguir afirmações de avaliações, e de avaliar a veracidade das afirmações $e$ a validez das avaliações. As narrativas construídas dependem de um sistema de distinções (socioculturais e lingüísticas) que definem as possibilidades ou oportunidades de ação. Estão condicionadas, finalmente, pelos estados de ânimo da liderança, que permitem declarar possibilidades não previstas por outros.

- A capacidade de declarar uma missão. A liderança se baseia na capacidade de fazer declarações e de com elas gerar novas realidades ou mundos possíveis. A missão do líder corresponde à declaração do que é possível, junto com o compromisso de fazer que aconteça. A missão depende tanto da leitura de mundo realizada quanto das próprias ações desencadeadas com base naquele compromisso, pois estas ações vão modificar o mundo e, com isso, a estrutura do possível.

- A capacidade de declarar uma organização e de nomear os indivíduos. Para atingir a missão, a liderança precisa recriar um agente coletivo, uma estrutura de coordenação da ação de diferentes indivíduos, com papéis e competências diferenciadas, uma organização. Uma organização gera um pano de fundo de compreensão com base no qual os indivíduos atuam na consecução de compromissos básicos. Uma organização também permite que se estabeleçam sistemas de recorrência, em particular, práticas sociais que são necessárias para o alcance de suas metas. Esta capacidade de declarar essa estrutura junto com a nomeação dos ocupantes dos cargos é uma delegação de poder que amplia o espaço para a liderança. Ao delegar poder, os líderes expandem sua capacidade de ação e a liderança, a qual passa a ser entendida como a necessidade de uma 
competência estendida e altamente disponível, como liderança disseminada, para além de uma visão limitada à condição de um dom misterioso de poucos indivíduos.

- A capacidade de comprometer-se a desenvolver a produção necessária à missão. Os líderes devem produzir as ações necessárias ao alcance da missão declarada. Devem cumprir as promessas feitas e devem gerar as condições de satisfação das mesmas. Esta conversação particular se chama produção. Para desenvolver a produção, é necessária a coordenação das ações de muitos indivíduos. A administração teria a competência de exercer essa coordenação. Os líderes e administradores aparecem como dois domínios conversacionais e de interesses diferentes. Os líderes aparecem mais conectados com a realização das declarações básicas e promessas que constituem uma organização. Os administradores aparecem mais envolvidos com o manejo da coordenação de promessas específicas que unem a organização. A responsabilidade final é sempre dos líderes, pois a eles cabe avaliar, sistematicamente, o alcance da delegação e o grau de satisfação das exigências de coordenação.

- A capacidade de cuidar da carreira dos funcionários, de sua identidade pessoal, de tomar conta das preocupações de outras pessoas. Não há liderança sem que as pessoas adotem como sua a missão organizacional, o que acontece quando as pessoas sentem que a missão declarada dá conta de suas próprias preocupações pessoais. O que os líderes declaram como possível expande o horizonte de possibilidades das pessoas, contribui para mudar a forma de avaliação de si mesmas, suas identidades, e sua forma de avaliação do mundo $e$ do futuro. Seus interesses passam a estar contemplados de forma diferente, conectados com a organização, e modificam os estados de ânimo das pessoas. Portanto, a liderança se fortalece na medida em que o líder subordina seu eu privado aos interesses da comunidade. Isto implica a transformação do líder em um espaço de possibilidades para a comunidade. A liderança não é um fenômeno individual, mas social.

- A capacidade de fazer alianças. As alianças respondem à necessidade de ampliar nossa capacidade de poder, ou de produzir mais e novas ações. Uma aliança faz parte da conversação sobre o poder. Baseia-se na avaliação dos jogadores de que, apoiando-se mutuamente, aumentarão suas capacidades particulares para a ação. Uma condição constitutiva das alianças é a confiança. Sem confiança não podemos fazer alianças. A confiança aparece como a avaliação que os jogadores fazem uns dos outros a respeito do cumprimento das promessas de mútuo apoio, conforme o acordado.

Flores (2000) reafirma que a liderança é um conjunto de juízos sobre alguém, baseados em observações da fala e das ações do mesmo. Esses juízos estão baseados em padrões sociais, também de caráter lingüístico. A liderança, para o autor, não é apenas uma avaliação, mas um domínio de ação em si mesmo. Uma vez que observamos as ações de alguém é que ocorre o fenômeno da liderança. Ora, as ações básicas da liderança são lingüísticas; os líderes falam às pessoas que eles dirigem. Mais ainda, é na interação lingüística onde acontece esse fenômeno.

Um líder é alguém que faz ofertas, pedidos, promessas. Um líder gera uma interpretação do presente, declara a possibilidade de um futuro diferente, e é capaz de gerar confiança em outras pessoas. Sem linguagem, essas ações não poderiam ser realizadas. 


\section{Análise geral dos modelos de liderança}

Destas linhas, podemos depreender que o novo paradigma de liderança acentua a necessidade de que esta tenha uma clara visão estratégica $e$ atributos de comunicação $e$ de negociação que a facultem a operar mais como fator de mobilização do que de imposição. Como insinuamos acima, é importante salientar que essa disponibilidade de uma visão privilegiada para a mudança (como vários autores culturalistas reafirmam) não pode ser entendida como uma visão personalista e manipuladora de liderança, mas como um olhar posto a serviço da argumentação crítica (para além da persuasão de base emocional), e construído na base da escuta ativa dos outros e de sua cultura.

A análise dos autores nos permitiu entender a visão da liderança transformadora como uma concepção um pouco personalista, característica de uma liderança visionária que atribui à comunicação o significado instrumental de um meio para convencer o coletivo ou para conseguir sua adesão. A comunicação está, aqui, a meio caminho entre o modelo da simples transmissão de informação e a comunicação discursiva bilateral. Há, porém, uma série de aspectos positivos na análise de liderança patrocinada por Bennis, como foi apontado acima.

O modelo de liderança da organização que aprende chama a atenção para a noção de liderança coletiva, cada vez mais aceita, acima de tudo, em organizações profissionais em que o poder está muito disseminado. Pensamos que essa escola apresenta uma perspectiva de análise fortemente pragmática, que lhe impede de aprofundar a temática da aprendizagem e da comunicação, de modo que sua visão de liderança não se articula explicitamente com a linguagem, como é o caso da corrente de Flores.

No entanto, temos de reconhecer que a corrente da aprendizagem organizacional tem feito esforços para incorporar o conceito de aprendizagem de Maturana (1998 apud Rivera, 2003), como processo contínuo de mudanças de comportamento induzido pela necessidade de um acoplamento estrutural entre indivíduo e meio. Dentro dessa ótica, a aprendizagem corresponde às mudanças ocorridas ao longo da vida em função de uma rede de interações com os outros e o meio, que se orienta para desafios diante de demandas recorrentes. Nesse processo histórico, tanto se dá a reprodução do indivíduo quanto do meio. A aprendizagem, como a cognição, está orientada para o fazer. Aprender é mudar para fazer. Aprender é fazer.

Visão semelhante à de Maturana é sustentada por Habermas (1987), para o qual a aprendizagem subentende o questionamento das representações simbólicas que fazem parte do mundo da vida das pessoas $e$ grupos, quando estas se tornam disfuncionais para dar conta dos problemas colocados pelo meio. A aprendizagem ligada ao fazer supõe a superação desses conteúdos e o surgimento de novos a partir do exercício de formas de discurso ou de argumentação crítica. Esse processo de aprendizagem é individual, mas subentende uma relação permanente para fora, uma intersubjetividade discursiva e uma relação com o objeto em geral, em situações de práxis (Artmann, 2001). Dito de outro modo, as capacidades de cognição e de socialização que tipificam o mundo subjetivo ou da 
personalidade (responsáveis pela aprendizagem individual) constituem estruturas que se alimentam principalmente da dinâmica das estruturas do mundo social, das normas e dos fatos sociais (Habermas, 1987 apud Rivera, 2003).

Para Maturana \& Habermas, o processo da aprendizagem se dá dentro e por meio da linguagem. É esta concepção da aprendizagem como fenômeno mediado pela comunicação inerente à linguagem que permite estabelecer uma articulação entre a concepção de liderança voltada para aprendizagem $e$ a concepção da liderança como fenômeno lingüístico. Devemos lembrar que uma parte importante da teoria da Pragmática Universal (teoria da comunicação habermasiana) foi construída com base na incorporação da teoria dos atos de fala, de Austin e Searle, o mesmo arcabouço teórico usado por Flores. Esta teoria estabelece a ponte entre Habermas e a concepção da liderança como fenômeno lingüístico.

Por fim, a partir de Rivera (2003), observamos que uma parte importante da escola da aprendizagem organizacional, particularmente a Ciência da Ação de Argyris (1992), declara, segundo Amatucci (1999), uma sorte de filiação à Teoria Crítica da Sociedade, mais especificamente à Teoria do Agir Comunicativo de Habermas. Assim, surge uma conexão interessante entre uma metateoria filosófica e uma escola de educação e comportamento organizacional, que ajuda a solidificar a metáfora das organizações que aprendem.

Desta maneira, consideramos que há uma ampla possibilidade de diálogo entre aqueles que sustentam a visão de uma liderança ecológica, coletiva, a serviço da aprendizagem, e a visão de liderança como fenômeno lingüístico. Há, entre essas visões, elos profundos no nível de sua moldura teórica.

\section{Liderança coletiva e saúde}

Com base nos seguintes argumentos: a não-padronização absoluta dos processos e resultados; a diversificação crescente dos seus produtos $e$ o alto nível de dependência que se estabelece entre serviços e categorias profissionais para a geração dos mesmos; a necessidade de acertar coletivamente mecanismos de avaliação; a forte autonomia profissional; o caráter fortemente interativo do trabalho final, sustentamos que o modelo mais adequado de gerenciamento, no setor saúde, é o comunicativo, que busca a negociação e o consenso (Rivera, 2003). Uma análise das organizações profissionais de saúde (Mintzberg, 1982) estabelece que o poder, nas mesmas, está fortemente disseminado, distribuído entre os vários centros operacionais, com ligações fracas. A fragmentação do processo de tomada de decisões, a necessidade de uma política de integração, a duplicidade de comando - administrativo e assistencial (ou governança clínica) -, recomendam o desenvolvimento de formas de negociação e de comunicação lateral, de práticas de discussão que permitam acertar a estratégia e um mínimo de integração.

Contandriopoulos et al. (2005) assumem que os hospitais são organizações pluralistas, pois não dependem de uma única liderança individual, envolvendo conselhos de administração, chefias de serviço e representações corporativas etc. Da mesma maneira, ao analisar os processos 
de regionalização e descentralização na França e no Quebec, destacam que o exercício da liderança não supõe apenas alargar a capacidade de decisão dos dirigentes locais e regionais, mas a necessidade de articular várias lideranças, situadas em diversas esferas de poder e níveis do sistema. Nesta perspectiva, sustentam o conceito de liderança coletiva como o mais adequado ao gerenciamento do setor.

A necessidade de integração, inerente à regionalização sanitária, põe em destaque a articulação de redes. Franco et al. (2004) entendem essas redes à luz de Flores (1989), como redes de petições e compromissos, formas de diálogos permeadas pela vontade do mútuo acolhimento, o que implica, segundo Teixeira (2003), a aceitação da demandas e das promessas do outro como reivindicações legítimas ou fundadas no princípio da correção normativa, ou seja, na adequação aos direitos, normas legais e princípios de convivência social. Esta formulação traz uma compreensão interessante sobre o acolhimento, baseada em sua percepção como uma rede de conversações (Artmann \& Rivera, 2006). Seriam redes intersubjetivas de pactuação, construídas a partir do seu reconhecimento como formas de reconhecimento do outro como legítimo outro na convivência (Maturana, 1998 apud Teixeira, 2003).

Para Campos (2003), um atendimento clínico de qualidade implica conciliar a clínica tradicional e a clínica do sujeito. Com base na noção de clínica ampliada, o autor sustenta que é muito importante conhecer aspectos genéricos dos processos saúde-doença-atenção, mas também aprender com a variação, saber escutar e saber perscrutar cada caso singular. As decisões devem ser ponderadas, valendo-se de opiniões de outros profissionais, exposição de incertezas, compartilhamento de dúvidas. Para esse autor, a clínica do sujeito demanda trabalho em equipe e um agir comunicativo. A escuta à subjetividade do paciente e a escuta ao seu contexto social trazem, para o interior da produção do cuidado individual, um senso da integralidade marcado pelas idéias de acolhimento e vínculo (Artmann \& Rivera, 2006). A clínica ampliada não deixa de conceder ao médico o caráter de uma liderança disseminada, que desenvolve uma rede intensiva de conversações com os usuários e com os outros profissionais das equipes consideradas necessárias para um cuidado mais integral e resolutivo.

Por fim, concordando com Contandriopoulos et al. (2005), a liderança das organizações sanitárias deveria deslocar-se do ápice organizacional ou hierárquico para operar como mais um fator de negociação do processo de relações interprofissionais, no seio da governança clínica, ou seja, do gerenciamento local dos centros operadores fortemente influenciado pelo saber profissional como poder. Esse tipo de enfoque está muito mais próximo de uma noção de liderança coletiva ou comunicativa, que se desenvolve por meio de rodas de conversação e jogos de linguagem, do que de uma visão de liderança visionária ou herói, egocêntrica. 


\section{Referências}

ARTMANN, E. Interdisciplinaridade no enfoque habermasiano: reflexões sobre planejamento e AIDS. Ciênc. Saúde Col., v.6, n.1, p.183-95, 2001.

ARTMANN, E.; RIVERA, F. J. U. Humanização no atendimento em saúde e gestão comunicativa. In: DESLANDES, S. (Org.). Humanização dos cuidados em saúde: conceitos, dilemas e práticas. Rio de Janeiro: Fiocruz, 2006. p.205-31.

AMATUCCI, M. Aprendizagem organizacional: encontro de tradições aponta para o futuro. In: LAS CASAS, A. (Org.). Novos rumos da administração. Petrópolis: Vozes, 1999. p.89-109.

AUSTIN, J. L. How to do things with the words. Oxford: Oxford, 1962.

ARGYRIS, C. Enfrentando defesas empresariais: facilitando o aprendizado organizacional. Rio de Janeiro: Campus, 1992.

BENNIS, W.; NANNUS, B. Diriger. Paris: InterEditions, 1985.

BENNIS, W.; NANUS, B. Líderes: estratégias para assumir a verdadeira liderança. São Paulo: Harbra, 1988.

BENNIS,W. A nova liderança. In: Coletânea HSM Management. Liderança e gestão de pessoas: autores e conceitos imprescindíveis. São Paulo: PUBLIFOLHA, 2001. p.31-46.

BENNIS,W.; BIEDERMAN, P. W. Os gênios da organização: as forças que impulsionam a criatividade das equipes de sucesso. Rio de Janeiro: Campus, 1999.

CAMPOS, G. W. S. Saúde Paidéia. São Paulo: Hucitec, 2003.

CONTANDRIOPOULOS, D.; CONTANDRIOPOULOS, A. P. ; DENIS, J. L.; VALETTE, A. L'hôpital en restructuration: regards croisés sur la France et le Québec. Montreal: Les Presses de l'Université de Montreal, 2005.

CROZIER, M.; SÉRIEYX, H. Du management panique à I'Entreprise du XXI siècle. Paris: Maxima, 1994.

ECHEVERRIA, R. Ontologia del lenguaje. Santiago: Dolmen, 1997.

ECHEVERRIA, R. La empresa emergente, la confianza y los desafios de la transformación. Buenos Aires: Granica, 2000.

FLORES, F. Inventando la empresa del siglo XXI. Santiago: Hataché, 1989.

FLORES, F. Una crisis em el liderazgo. In: CREANDO NUEVOS MUNDOS, 2004, Santiago. Palestra... Santiago, 2004. Disponível em: <http://www.fernando.flores.cl/node/1>. Acesso em: 10 dez. 2005.

FRANCO, T. B.; BUENO, W. S.; MERHY, E. E. O acolhimento e os processos de trabalho em saúde: o caso de Betim (MG). In: MEHRY, E.E.; MAGALHÃES JR., H. M.;RIMOLI, J.; FRANCO, T. B.; BUENO, W. S. (Orgs.). O trabalho em saúde: olhando e experenciando o SUS no cotidiano. São Paulo: Hucitec, 2004, p.37-54.

HABERMAS, J. Teoria de la acción comunicativa. Madrid: Taurus, 1987.

MATURANA, H. Emoções e linguagem na educação e na política. Belo Horizonte: Ed. UFMG, 1998.

MATURANA, H. Biosphere, homosphere and robosphere: what has to do with business? Disponível em: <http://www.fieldbook.com/sol.html>. Acesso em: 20 jan. 2006.

MINTZBERG, H. Crafting strategy. Harvard Bus. Rev., v.5, p.73-89, 1985.

MINTZBERG, H. Structure et dynamique des organizations. Paris: Éditions d'Organization, 1982.

MOTTA, P. R. Gestão contemporânea: a ciência e a arte de ser dirigente. Rio de Janeiro: Record, 1991. 
RIVERA, F. J. U.; ARTMANN, E.

RIVERA, F. J. U. Análise estratégica em saúde e gestão pela escuta. Rio de Janeiro: Fiocruz, 2003.

TEIXEIRA, R. R. O acolhimento num serviço de saúde entendido como uma rede de conversações. In: PINHEIRO, R.; MATTOS, R. A. (Orgs.). Construção da integralidade: cotidiano, saberes e práticas de saúde. Rio de Janeiro: IMS-UERJ/ABRASCO, 2003. p.89-111.

SEARLE, J.R. A taxonomy of illocucionary acts in language, mind and knowledge. Minneapolis: University of Minnesota Press, 1976.

SENGE, P. O novo trabalho do líder: construindo organizações que aprendem. In: STARKEY, K. Como as organizações aprendem: relatos de sucessos das grandes empresas. São Paulo: Zumble/Futura, 1997. p.342-75.

SENGE, P. A dança das mudanças: os desafios de manter o crescimento e o sucesso em organizações que aprendem. Rio de Janeiro: Zumble/Campus, 2000.

STARKEY, K. Como as organizações aprendem: relatos de sucessos das grandes empresas. São Paulo: Zumble/Futura, 1997.

RIVERA, F. J. U.; ARTMANN, E. El liderazgo como intersubjetividad lingüística. Interface Comunic., Saúde, Educ., v.10, n.20, p.411-26, jul/dez 2006.

Este trabajo es una síntesis de varias concepciones de liderazgo e su objetivo es destacar la importancia creciente en la literatura especializada de la visión del líder como instancia de aprendizaje organizacional, de base colectiva, y como coordinador de procesos de comunicación lingüística orientados al entendimiento sobre la misión, la estructura y la dinámica de funcionamiento de las organizaciones. El artículo sustenta que el liderazgo debe desarrollar, además de las capacidades de análisis estratégico, competencias comunicativas y apoyar el cambio para gerenciar con más eficacia las relaciones intersubjetivas de los actores organizacionales, para que la organización sea competente.

PALABRAS CLAVE: liderazgo. administración de personal. organizaciones.

Recebido em 29/03/06. Aprovado em 08/08/06. 